\title{
In-Situ TEM Annealing Observation of Helium Bubble Evolution in Pre-Irradiated FeCoNiCrTi 0.2 Alloys
}

\author{
Huanhuan He, Zhiwei Lin, Shengming Jiang, Xiaotian Hu, Jian Zhang * and Zijing Huang * \\ College of Energy, Xiamen University, Xiamen 361005, China; 32420181153444@stu.xmu.edu.cn (H.H.); \\ 32420181153424@stu.xmu.edu.cn (Z.L.); 32420191152363@stu.xmu.edu.cn (S.J.); \\ 32420201152830@stu.xmu.edu.cn (X.H.) \\ * Correspondence: zhangjian@xmu.edu.cn (J.Z.); fritz@xmu.edu.cn (Z.H.)
}

Citation: He, H.; Lin, Z.; Jiang, S.; Hu, X.; Zhang, J.; Huang, Z. In-Situ TEM Annealing Observation of Helium Bubble Evolution in Pre-Irradiated FeCoNiCrTi ${ }_{0.2}$ Alloys. Materials 2021, 14, 3727. https:// doi.org/10.3390/ma14133727

Academic Editors: Jeong Min Park and Jongun Moon

Received: 9 June 2021

Accepted: 1 July 2021

Published: 2 July 2021

Publisher's Note: MDPI stays neutral with regard to jurisdictional claims in published maps and institutional affiliations.

Copyright: (c) 2021 by the authors. Licensee MDPI, Basel, Switzerland. This article is an open access article distributed under the terms and conditions of the Creative Commons Attribution (CC BY) license (https:// creativecommons.org/licenses/by/ $4.0 /)$.

\begin{abstract}
The FeCoNiCrTi ${ }_{0.2}$ high-entropy alloys fabricated by vacuum arc melting method, and the annealed pristine material, are face centered cubic structures with coherent $\gamma^{\prime}$ precipitation. Samples were irradiated with $50 \mathrm{keV} \mathrm{He}{ }^{+}$ions to a fluence of $2 \times 10^{16}$ ions $/ \mathrm{cm}^{2}$ at $723 \mathrm{~K}$, and an in situ annealing experiment was carried out to monitor the evolution of helium bubbles during heating to 823 and $923 \mathrm{~K}$. The pristine structure of $\mathrm{FeCoNiCrTi}_{0.2}$ samples and the evolution of helium bubbles during in situ annealing were both characterized by transmission electron microscopy. The annealing temperature and annealing time affect the process of helium bubbles evolution and formation. Meanwhile, the grain boundaries act as sinks to accumulate helium bubbles. However, the precipitation phase seems have few effects on the helium bubble evolution, which may be due to the coherent interface and same structure of $\gamma^{\prime}$ precipitation and matrix.
\end{abstract}

Keywords: $\mathrm{FeCoNiCrTi}{ }_{0.2}$; high-entropy alloys; $\mathrm{He}^{+}$ions irradiation; helium bubbles

\section{Introduction}

Recently, high-entropy alloys (HEAs) have been regarded as one of the potential nuclear structural candidate materials due to their excellent irradiation resistance [1-5]. In nuclear reactors, $(n, \alpha)$ a transmutation reaction will produce a number of helium atoms, which are easy to precipitate at grain boundaries and dislocations, forming helium bubbles and voids, resulting in material swelling and material failure [6]. At present, some progress has been made in the diffusion of He atoms and the growth mechanism of helium bubbles in high-entropy alloy materials [7-12]. Meanwhile, FeCoNiCr has been proven by its excellent resistance to heavy ions and He-ion irradiation $[8,13]$. Duan et al. found that the ultra-fine grained $\mathrm{FeNiCoCr}$ alloys remains stable under the irradiation damage up to 58 dpa in the temperature of $573 \mathrm{~K}$ and $773 \mathrm{~K}$, which indicated that an excellent irradiation resistance of Fe-Co-Ni-Cr HEAs [13]. Moreover, previous studies have shown that the addition of Ti can form $\gamma^{\prime}$ precipitations in FeCoNiCr HEAs, which will enhance the strength of FeCoNiCr HEAs. Han et al. observed the composition evolution of the $\gamma^{\prime}$ precipitations at different aging duration in $\mathrm{FeCoNiCrTi}_{0.2}$ alloys, and proved that the $\gamma^{\prime}$ precipitations have a $(\mathrm{CoFeCrNi})_{3} \mathrm{Ti}$ phase [14]. Chen et al. found that $1 / 3<111>$ dislocation loops were formed and the helium bubbles were observed under the irradiation of $275 \mathrm{keV} \mathrm{He}^{+}$at $673 \mathrm{~K}$ [15]. Additionally, they also compared the $\mathrm{FeCoNiCrTi}_{0.2}$ alloys with the $\mathrm{FeCoNiCr}$ alloys and $\mathrm{FeCoNiCr}(\mathrm{Al} / \mathrm{Cu})_{0.2} \mathrm{HEAs}$ under $\mathrm{He}^{+}$ion irradiation [16]. However, the size of $\gamma^{\prime}$ precipitates is below $10 \mathrm{~nm}$ in those studies, where the interface effects of precipitates and matrix is hard to distiguish in TEM samples with $100 \mathrm{~nm}$ thickness. Meanwhile, the evolution of the helium bubbles is rarely studied by in situ annealing experiments. Therefore, this article studies the $\mathrm{He}^{+}$ion irradiation on $\mathrm{FeCoNiCrTi}_{0.2}$ alloys with larger size $\gamma^{\prime}$ precipitations and performs the post-irradiation in situ annealing observation in order to better understand the influence of the $\gamma^{\prime}$ precipitations on the behaviors of the helium bubbles. 


\section{Materials and Methods}

The HEA FeCoNiCrTi 0.2 were fabricated by vacuum arc melting with a mixture of pure metals (purity > $99.99 \mathrm{wt} . \%$ ). These ingots were remelted at least five times to homogenize the ingredients and were drop-cast into a copper mold. The ingots were subsequently annealed at $1423 \mathrm{~K}$ for $2 \mathrm{~h}$ in a purity $99.99 \%$ Ar atmosphere and cooled in the furnace. Before $\mathrm{He}^{+}$irradiation, the annealed samples were ground to a thickness of about $30 \mu \mathrm{m}$, punched into disks of $3 \mathrm{~mm}$ diameter and then thinned by twin-jet electro-polishing with a voltage of $20 \sim 30 \mathrm{~V}$ in a solution of $5 \%$ perchloric acid $+35 \% \mathrm{~N}$-butanol $+60 \%$ Ethanol at the temperature of about $-40{ }^{\circ} \mathrm{C}$.

The well-polished tansmission electron microscope (TEM) samples were irradiated with $50 \mathrm{keV} \mathrm{He}{ }^{+}$ions at $723 \mathrm{~K}$ to a total fluence of $2 \times 10^{16}$ ions $/ \mathrm{cm}^{2}$ with ion flux of $\sim 1.85 \times 10^{12}$ ions $/\left(\mathrm{cm}^{2} \cdot \mathrm{s}\right)$ by the NEC-400 kV ion implanter at Xiamen University (National Electrostatics Corp., Middleton, WI, USA). In situ TEM annealing experiments were performed at a temperature of $823 \mathrm{~K}$ for $30 \mathrm{~min}$, followed by heating to $923 \mathrm{~K}$ for 30 min at an increasing temperature rate of $50 \mathrm{~K} / \mathrm{min}$, using a Gatan 652 double-tilt heating holder. Characterizations of pristine samples and helium-bubble evolution are examined by an FEI Tecnai F30 microscope with a double-tilt specimen holder, operated at $300 \mathrm{kV}$, where the degree of under-focus is about $3 \mu \mathrm{m}$ to observe the helium bubbles.

\section{Results and Discussion}

Figure 1 presents the TEM microstructures of the annealed FeCoNiCrTi ${ }_{0.2}$ samples, including bright-field image and its corresponding selected area electron diffraction (SAED) pattern and EDS results from a region containing the matrix and precipitates. In the brightfield image, the precipitates of approximately $60-80 \mathrm{~nm}$ can be clearly observed. The corresponding SAED pattern along zone axis $\mathrm{z}=[110]$ shows that the precipitates have an $\mathrm{L}_{2}$ structure ( $\gamma^{\prime}$ phase), which is completely coherent with the face centered cubic crystal structure of matrix with a lattice constant of 3.6061 $\AA$. The STEM-EDS results indicated that the main elements of the $\gamma^{\prime}$ precipitation are $\mathrm{Ni}$ and $\mathrm{Ti}$; the element $\mathrm{Co}$ is partitioned into the $\gamma^{\prime}$ precipitation, the distribution of elements Fe and $\mathrm{Cr}$ is poor. The atomic percentage of the Ni and Ti elements is about 3:1. These results are consistent with the previously reported structure of FeCoNiCrTi 0.2 samples [14].
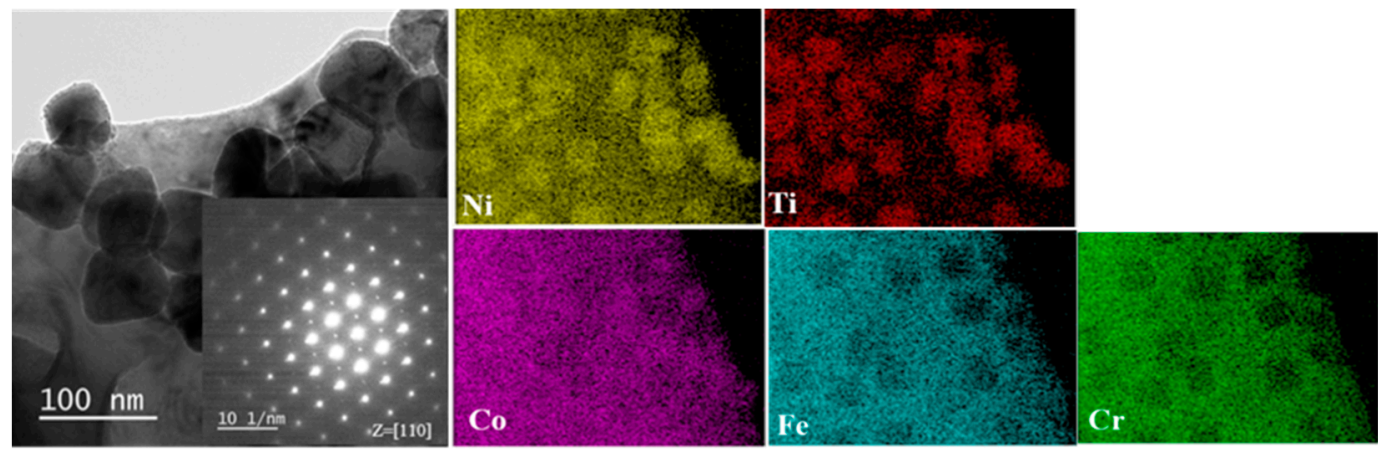

Figure 1. The micro-structure of pristine $\mathrm{FeCoNiCrTi}_{0.2}$ alloys under $\mathrm{TEM}$ characterizations.

Figure 2 shows the helium bubbles and defects generated inside the FeCoNiCrTi $i_{0.2}$ samples under $\mathrm{He}^{+}$ions irradiation at $723 \mathrm{~K}$. To better examine the distribution and size of helium bubbles produced by $\mathrm{He}^{+}$irradiation, the TEM images are performed under under-focus and over-focus, respectively. In Figure 2a, helium bubbles appear as black dots with white edges at the over-focus state. In contrast, helium bubbles are white dots with black edges under the under-focus condition, shown in Figure $2 \mathrm{~b}$. Inside the FeCoNiCrTi ${ }_{0.2}$ samples, the helium bubbles present as dispersed distribution and the helium bubbles near the defects tend to gather together. The diameter distribution of helium bubbless in Figure 2a,b can be fitting well with Gaussian distribution (see Figure 2c), and the mean 

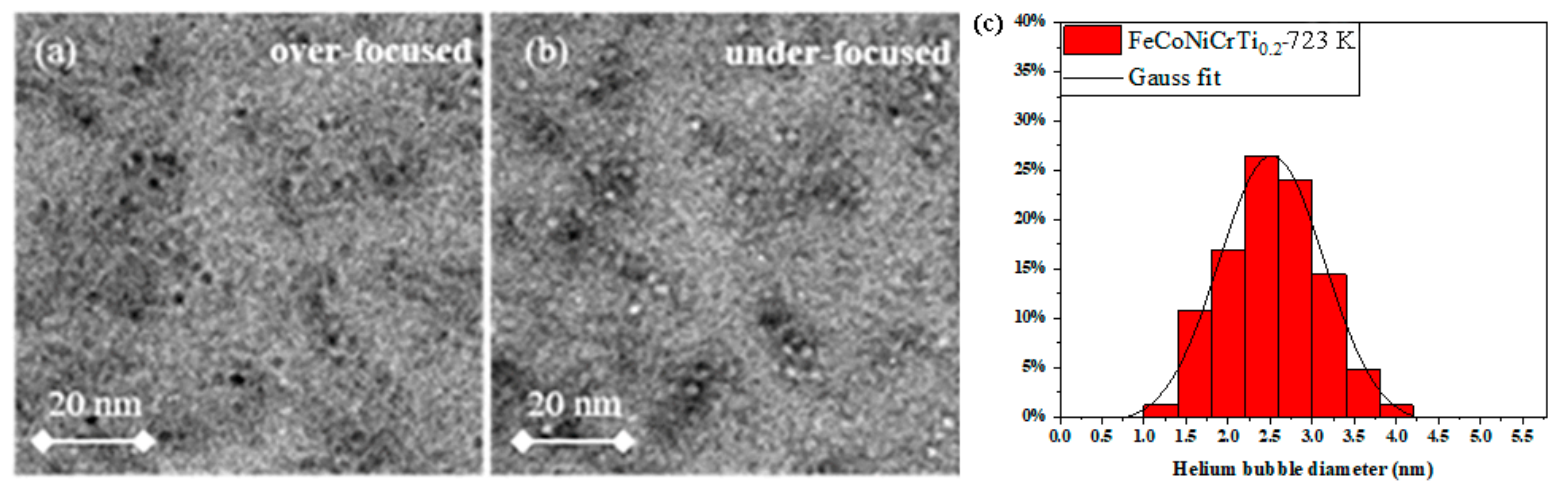

Figure 2. Distribution of helium bubbles and Gaussian fitting in the FeCoNiCrTi 0.2 alloys after pre-irradiation at $723 \mathrm{~K}$. (a) over-focused; (b) under-focused; (c) He bubbles distribution.

Figure 3 shows the evolution of helium bubbles observed at the grain boundary during in situ annealing at the $823 \mathrm{~K}$ and $923 \mathrm{~K}$. Before annealing (Figure 3a), the helium bubbles near the defects are more concentrated, which is the same as the result in Figure 2. After annealing at $823 \mathrm{~K}$ for $30 \mathrm{~min}$ (Figure $3 \mathrm{~b}$ ), the number of helium bubbles decreases and the helium bubbles tend to move to the grain boundary labeled with white broken lines in Figure 3. The annealing time has an influence on the nucleation and growth of helium bubbles, and some of the helium bubbles diffuse and release to the free surface. Actually, the grain boundary and the sample surface can act as the effective sinks for helium atoms. After holding at $923 \mathrm{~K}$ for $5 \mathrm{~min}$, there are more bubbles at the grain boundary than inside the grain (Figure 3c). After the annealing time reaches $20 \mathrm{~min}$ at $923 \mathrm{~K}$, the surface is completely destroyed (Figure $3 b$ ). In the in situ annealing process, the size of the helium bubbles gradually increases with the increase in the holding time and heating temperature. The specific values of the helium bubbles size are summarized in Table 1. Meanwhile, the helium bubble density will decrease with the annealing time during the migration and coalescence process. The areal densities of helium bubbles are summarized in Table 1. It was found that the helium areal density will decrease slowly at $823 \mathrm{~K}$ with annealing time, while the helium areal density will substantially decrease with the annealing temperature increase to $923 \mathrm{~K}$.

In addition, the distribution of helium bubbles in the observed irradiation area is relatively homogeneous, as shown in Figures 2 and 3. This indicates that the $60-80 \mathrm{~nm} \gamma^{\prime}$ precipitations seem have few effects on the helium bubbles' evolution, which may be due to the coherent interface and same structure of $\gamma^{\prime}$ precipitation and matrix. On the other hand, the $\gamma^{\prime}$ precipitations can enhance the strength of the alloys without affecting the evolution of the helium bubbles, which provides us with new prospects for high strength and radiation-tolerant materials design.

At $923 \mathrm{~K}$, the generation and evolution of voids with quadrilateral or hexagonal shapes are observed during annealing, compared with annealing at $823 \mathrm{~K}$ where the evolution of helium bubbles is only observed at $823 \mathrm{~K}$. The size and number of voids increase as the holding time increases, as shown in Figure 3e-f.

Table 1. The size of helium bubbles under different annealing times at $823 \mathrm{~K}$ and $923 \mathrm{~K}$.

\begin{tabular}{cccccc}
\hline \multirow{2}{*}{$823 \mathrm{~K}$} & Annealing time (min) & 5 & 10 & 20 & 30 \\
& Helium bubble size $(\mathrm{nm})$ & $3.85 \pm 0.34$ & $4.03 \pm 0.41$ & $4.06 \pm 0.15$ & $4.08 \pm 0.08$ \\
& Areal density of helium bubbles $\left(\mathrm{nm}^{-2}\right)$ & $1.9 \times 10^{-2}$ & $2.2 \times 10^{-2}$ & $1.43 \times 10^{-2}$ & $1.01 \times 10^{-2}$ \\
\hline \multirow{2}{*}{$923 \mathrm{~K}$} & Annealing time $(\mathrm{min})$ & 5 & 7 & 10 & 15 \\
& Helium bubble size $(\mathrm{nm})$ & $4.41 \pm 0.06$ & $4.43 \pm 0.11$ & $4.53 \pm 0.19$ & $4.76 \pm 0.17$ \\
& Areal density of helium bubbles $\left(\mathrm{nm}^{-2}\right)$ & $6.1 \times 10^{-3}$ & $6.0 \times 10^{-3}$ & $5.1 \times 10^{-3}$ & $4.2 \times 10^{-3}$ \\
\hline
\end{tabular}




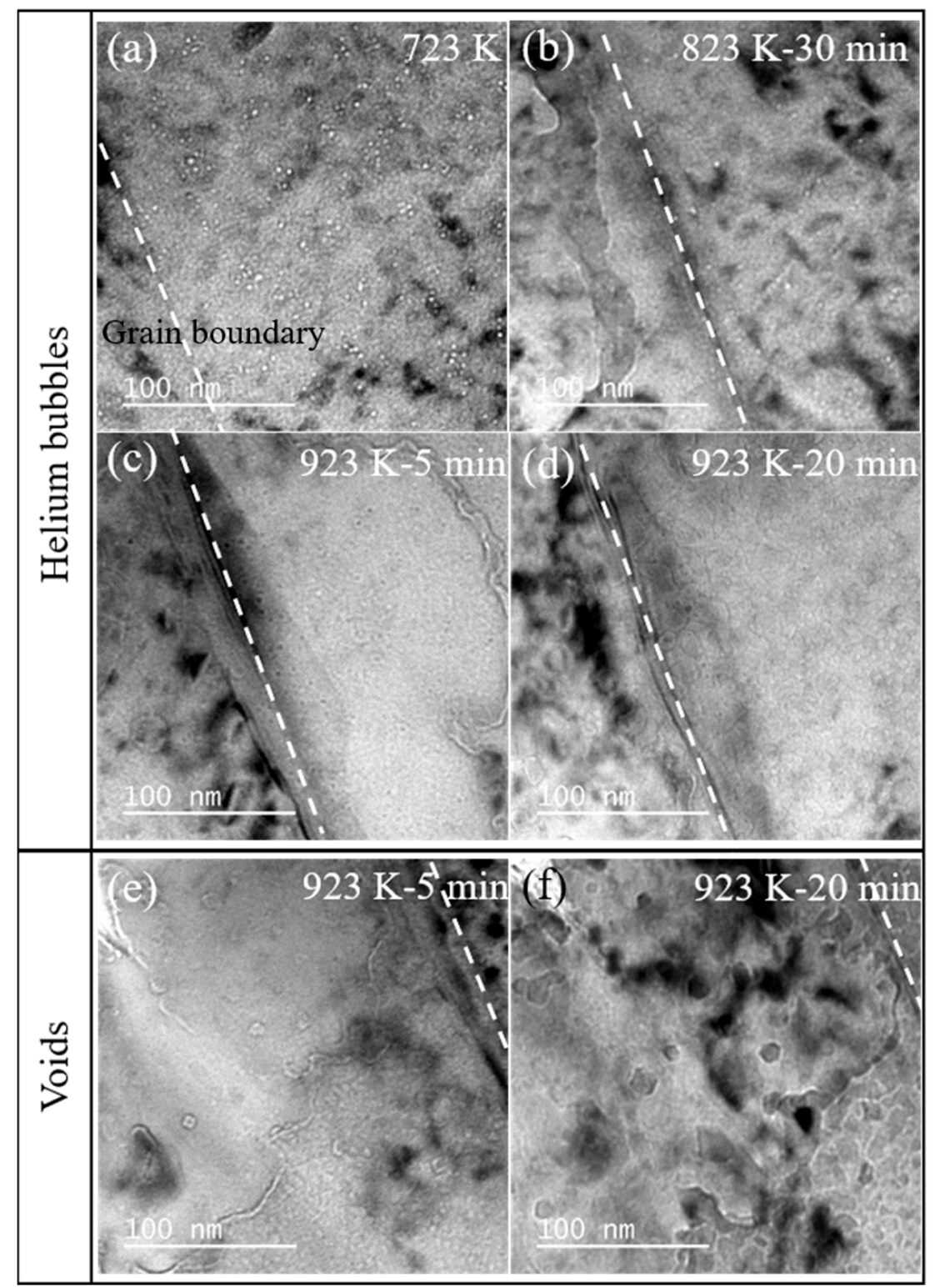

Figure 3. (a-d) The evolution of helium bubbles during in situ annealing at $823 \mathrm{~K}$ and $923 \mathrm{~K}$; (e-f) the evolution of voids at $923 \mathrm{~K}$ in the $\mathrm{FeCoNiCrTi} i_{0.2}$ alloys.

According to the above results, the helium bubble sizes at different temperatures are plotted and fitted with annealing time to further explore the helium bubble evolution behaviors in Figure 4. At given temperatures and helium concentrations, the relationship between the annealing time and the size of helium bubbles can be expressed by the following power function [17]:

$$
R_{b}=A \times t^{n}+R_{0}
$$

where $R_{b}$ is the mean bubble diameter in nanometers at temperature $b, t$ is the annealing temperature, and $R_{0}$ is the original bubble diameter. The final fitting formula is as follows:

$$
\begin{aligned}
& R_{823 \mathrm{~K}}=1.25388 \times t^{0.06887}+2.5 \\
& R_{923 \mathrm{~K}}=0.09236 \times t^{0.71588}+4.08
\end{aligned}
$$




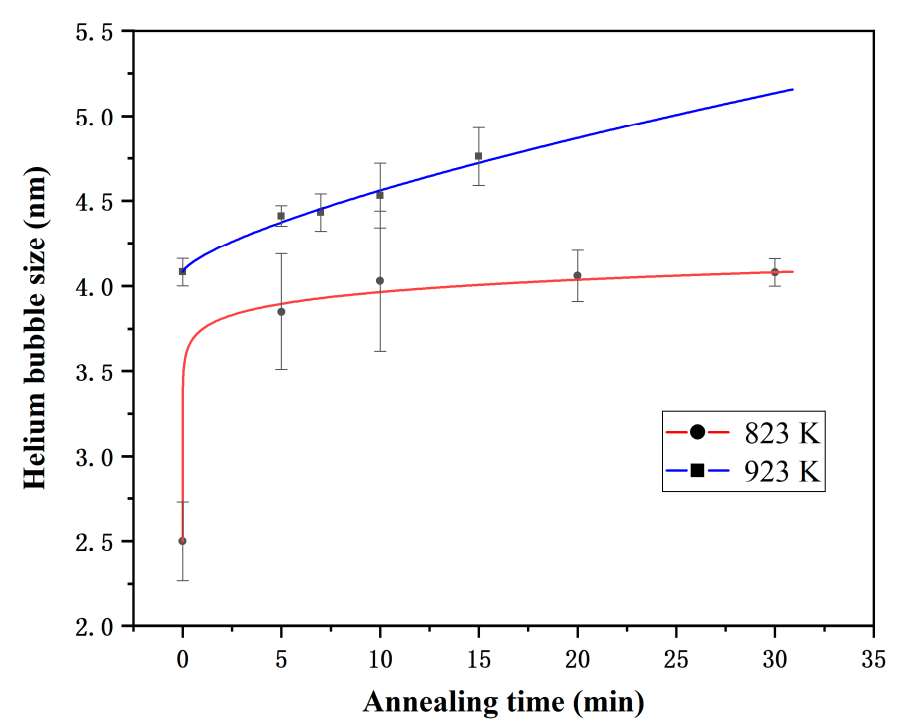

Figure 4. Evolution of He bubbles sizes with annealing times at different temperatures.

Obviously, the longer the annealing time, and the higher the annealing temperature, the faster the growth rate of helium bubbles. Previous studies prove that the coarsening mechanism of helium bubbles is divided into two types: migration and coalescence (MC) and Ostwald ripening (OR) [18]. Additionally, the melting point of FeCoNiCr is around $1695 \mathrm{~K}$ [19], which means that the experimental temperature in this study is between $0.2-0.5 \mathrm{~T}_{\mathrm{m}}$. In this study, the migration and coalescence (MC) mechanism is effective at the temperatures of $0.2-0.5 \mathrm{~T}_{\mathrm{m}}$ [11]. The temperature dependence on the final diameter follows an Arrhenius relationship [20]:

$$
D=D_{0} \exp \left(-\frac{E_{a}}{k T}\right)
$$

where $D$ is the bubble diameter, $k$ is the Boltzmann constant, $E_{a}$ is the effective activation energy of coarsening, and $T$ is the annealing time. The effective activation energy $E_{a}$ of bubble coarsening can be calculated as $1.638 \mathrm{eV}$. Meanwhile, a multi-element nucleation model is proposed to describe the stability of helium bubbles, as follows [8,12]:

$$
\begin{gathered}
C_{B}(t \rightarrow \infty) \sim 2 C_{B}^{*} \propto\left(\frac{P_{\mathrm{He}}}{t^{\gamma} c_{\mathrm{Hel}}^{*}}\right)^{\frac{1}{\gamma+1}} / D_{\mathrm{Hel}} \\
\overline{r_{B}}(\mathrm{t} \rightarrow \infty) \propto\left[D_{\mathrm{Hel}} c_{\mathrm{Hel}}^{*} 1 /(\gamma+1)\left(\frac{P_{\mathrm{He}}}{t^{\gamma}}\right)^{\frac{\gamma}{\gamma+1}} t^{\gamma+1}\right]^{1 / \beta}
\end{gathered}
$$

where $C_{B}$ is the density of helium bubbles, $C_{\mathrm{Hel}}{ }^{*}$ is the helium concentration in solution at nucleation peak, $\overline{r_{B}}$ is the mean diameter of helium bubbles, $P_{\mathrm{He}}$ is the production rate of helium atoms, $t$ is the helium bubble evolution time. The formula shows that the larger of the helium bubble diffusion coefficient $\left(D_{\mathrm{Hel}}\right)$, the larger of the helium bubble size and the lower of the bubble density. The increase in annealing temperature results in a larger helium bubble diffusion coefficient and a larger bubble size, which is consistent with our experimental results.

Previous analysis illustrated that the experimental temperature is approximately $0.2-0.5 \mathrm{~T}_{\mathrm{m}}$, which means that migration rate of vacancies caused by irradiation and thermal effect will be significantly improved. Trinkaus et al. counted and proved that the diffusion of helium atoms is dominated by the vacancy mechanism at the temperature of $0.2-0.5 \mathrm{~T}_{\mathrm{m}}$ [11]. After reaching this temperature, the vacancies in the sample quickly migrate and merge to form voids. Meanwhile, the size and number of cavities increase 
as the holding time increases. In addition, the $\mathrm{FeCoNiCrTi}_{0.2}$ samples possess an FCC structure containing $\gamma^{\prime}$ precipitation with a coherent $\mathrm{L1}_{2}-\mathrm{Ni}_{3} \mathrm{Ti}$ structure with the matrix. Total dislocations with a Burgers vector $a / 2\langle 110\rangle$ and partial dislocation including Shockley partial dislocation and Frank partial dislocation will be introduced by irradiation. In FCC-structure crystals, Shockley partial dislocation possess a burgers vector $a / 6\langle 11 \overline{2}\rangle$ and Frank partial dislocation is $a / 3\langle 111\rangle$ on the $\{111\}$ crystal plane. These dislocations in different directions react with each other to form a tetrahedron or octahedron, resulting in the quadrilateral or hexagonal voids shape.

\section{Conclusions}

In summary, we have investigated the process of bubble evolution and formation under $50 \mathrm{keV} \mathrm{He}^{+}$irradiation at $723 \mathrm{~K}$ in $\mathrm{FeCoNiCrTi}_{0.2}$ alloys. Helium bubbles were observed when the samples were pre-irradiated at $723 \mathrm{~K}$. The diameter of helium bubbles gradually increased and fit well with the Gaussian distribution. The $60-80 \mathrm{~nm} \gamma^{\prime}$ precipitations seem have few effects on the helium evolution, which may be due to the coherent interface and same structure of $\gamma^{\prime}$ precipitation and matrix. Additionally, the helium bubble sizes at different temperatures are plotted and fit well with the empirical power formula. Meanwhile, the migration and coalescence (MC) mechanism is applied to interpret the in situ annealing observations in this study. In addition, the generation and evolution of voids were observed during annealing at $923 \mathrm{~K}$.

Author Contributions: H.H. performed the experiment, analyzed the data, and drafted the manuscript. Z.L. helped with the experiment design and participated in manuscript preparation. S.J. and X.H. helped with the experiment operation. J.Z. supervised the project, checked the data and revised the manuscript, Z.H. checked the data, analyzed the data. All authors have read and agreed to the published version of the manuscript.

Funding: This research was funded by the National Natural Science Foundation of China, grant No. 12075200, and partial support from the Joint Funds of the Natural Science Foundation of China, grant No. U1967206.

Institutional Review Board Statement: Not applicable.

Informed Consent Statement: Not applicable.

Data Availability Statement: The data presented in this study are available on request from the corresponding author.

Acknowledgments: The authors are thankful to Jinchi Huang and Zhehui Zhou from Xiamen University for assistance in ion irradiation experiment.

Conflicts of Interest: The authors declare no conflict of interest.

\section{References}

1. Nagase, T.; Rack, P.D.; Noh, J.H.; Egami, T. In-situ TEM observation of structural changes in nano-crystalline CoCrCuFeNi multicomponent high-entropy alloy (HEA) under fast electron irradiation by high voltage electron microscopy (HVEM). Intermetallics 2015, 59, 32-42. [CrossRef]

2. Nagase, T.; Anada, S.; Rack, P.D.; Noh, J.H.; Yasuda, H.; Mori, H.; Egami, T. Electron-irradiation-induced structural change in Zr-Hf-Nb alloy. Intermetallics 2012, 26, 122-130. [CrossRef]

3. Lu, C.Y.; Niu, L.L.; Chen, N.J.; Jin, K.; Yang, T.N.; Xiu, P.Y.; Zhang, Y.W.; Gao, F.; Bei, H.B.; Shi, S.; et al. Enhancing radiation tolerance by controlling defect mobility and migration pathways in multicomponent single-phase alloys. Nat. Commun. 2016, 7, 13564. [CrossRef] [PubMed]

4. Lin, Y.P.; Yang, T.F.; Lang, L.; Shan, C.; Deng, H.Q.; Hu, W.Y.; Gao, F. Enhanced radiation tolerance of the Ni-Co-Cr-Fe high-entropy alloy as revealed from primary damage. Acta Mater. 2020, 196, 133-143. [CrossRef]

5. Lu, C.Y.; Yang, T.N.; Jin, K.; Velisa, G.; Xiu, P.Y.; Peng, Q.; Gao, F.; Zhang, Y.W.; Bei, H.B.; Weber, W.J.; et al. Irradiation effects of medium-entropy alloy NiCoCr with and without pre-indentation. J. Nucl. Mater. 2019, 524, 60-66. [CrossRef]

6. Yang, L.X.; Ge, H.L.; Zhang, J.; Xiong, T.; Jin, Q.Q.; Zhou, Y.T.; Shao, X.H.; Zhang, B.; Zhu, Z.W.; Zheng, S.J.; et al. High He-ion irradiation resistance of $\mathrm{CrMnFeCoNi} \mathrm{high-entropy} \mathrm{alloy} \mathrm{revealed} \mathrm{by} \mathrm{comparison} \mathrm{study} \mathrm{with} \mathrm{Ni}$ and 304SS. J. Mater. Sci. Technol. 2019, 35, 300-305. [CrossRef] 
7. Wang, Y.; Zhang, K.; Feng, Y.H.; Li, Y.S.; Tang, W.Q.; Wei, B.C. Evaluation of radiation response in CoCrFeCuNi high-entropy alloys. Entropy 2018, 20, 835. [CrossRef] [PubMed]

8. Chen, D.; Zhao, S.J.; Sun, J.R.; Tai, P.F.; Sheng, Y.B.; Zhao, Y.L.; Yeli, G.; Lin, W.T.; Liu, S.F.; Kai, W.; et al. Diffusion controlled helium bubble formation resistance of FeCoNiCr high-entropy alloy in the half-melting temperature regime. J. Nucl. Mater. 2019, 526, 151747. [CrossRef]

9. Lu, Y.P.; Huang, H.F.; Gao, X.Z.; Ren, C.L.; Gaob, J.; Zhang, H.Z.; Zheng, S.J.; Jin, Q.Q.; Zhao, Y.H.; Lu, C.Y.; et al. A promising new class of irradiation tolerant materials: Ti2ZrHfV0.5Mo0.2 high-entropy alloy. J. Mater. Sci. Technol. 2019, 35, 369-373. [CrossRef]

10. Hu, J.T.; Zhang, J.W.; Zhang, J.J.; Xiao, H.Y.; Xie, L.; Shen, H.H.; Li, P.C.; Sun, G.G.; Zu, X.T. Theoretical combined experimental study of unique He behaviors in high-entropy alloys. Inorg. Chem. 2021, 60, 1388-1397. [CrossRef] [PubMed]

11. Trinkaus, H.; Singh, B.N. Helium accumulation in metals during irradiation-Where do we stand? J. Nucl. Mater. 2003, 323, 229-242. [CrossRef]

12. Trinkaus, H. Modeling of helium effects in metals-High-temperature embrittlement. J. Nucl. Mater. 1985, 133, 105-112. [CrossRef]

13. Duan, J.; He, L.; Fu, Z.; Hoffman, A.; Wen, H. Microstructure, strength and irradiation response of an ultra-fine grained FeNiCoCr multi-principal element alloy. J. Alloys Compd. 2020, 851, 156796. [CrossRef]

14. Han, B.; Wei, J.; Tong, Y.; Chen, D.; Zhao, Y.L.; Wang, J.; He, F.; Yang, T.; Zhao, C.; Shimizu, Y.; et al. Composition evolution of gamma prime nanoparticles in the Ti-doped CoFeCrNi high entropy alloy. Scr. Mater. 2018, 148, 42-46. [CrossRef]

15. Chen, D.; Tong, Y.; Wang, J.; Han, B.; Zhao, Y.L.; He, F.; Kai, J.J. Microstructural response of He+ irradiated FeCoNiCrTi0.2 high-entropy alloy. J. Nucl. Mater. 2018, 510, 187-192. [CrossRef]

16. Chen, D.; Zhao, S.; Sun, J.; Tai, P.; Sheng, Y.; Yeli, G.; Zhao, Y.; Liu, S.; Lin, W.; Kai, W.; et al. Effects of minor alloying addition on He bubble formation in the irradiated FeCoNiCr-based high-entropy alloys. J. Nucl. Mater. 2020, 542, 152458. [CrossRef]

17. Chen, Y.; Li, Y.P.; Ran, G.; Wu, L.; Ye, C.; Han, Q.; Wang, H.; Du, H.L. In-situ TEM observation of the evolution of dislocation loops and helium bubbles in a pre helium irradiated FeCrAl alloy during annealing. Prog. Nucl. Energy 2020, 129, 103502. [CrossRef]

18. Schroeder, H.; Fichtner, P.F.P. On the coarsening mechanisms of helium bubbles-Ostwald ripening versus migration and coalescence. J. Nucl. Mater. 1991, 179, 1007-1010. [CrossRef]

19. Wu, Z.; Bei, H.; Otto, F.; Pharr, G.M.; George, E.P. Recovery, recrystallization, grain growth and phase stability of a family of FCC-structured multi-component equiatomic solid solution alloys. Intermetallics 2014, 46, 131-140. [CrossRef]

20. Chernikov, V.N.; Trinkaus, H.; Ullmaier, H. Helium bubbles in nickel annealed at T >0.7 T(m). J. Nucl. Mater. 1997, 250, 103-110. [CrossRef] 